\title{
Rare uterine didelphis and cervical pregnancy
}

\author{
Yunus KATIRCI*i®, Hüseyin YAYLACI®, Aybeniz İSMAYILLI ${ }^{\circledR}$, Ayșe Zehra ÖZDEMİR
}

Department of Gynecology and Obstetrics, Faculty of Medicine, Ondokuz Mayıs University, Samsun, Turkey

\begin{tabular}{l} 
Received: $04.05 .2021 \quad \bullet \quad$ Accepted/Published Online: 21.05 .2021 \\
\hline Abstract \\
Due to increased vaginal bleeding, a surgical operation was performed on a woman with cervical pregnancy. A diagnosis of uterine \\
didelphis (UD) was made during surgery. The hypogastric arteries on both sides were ligated. After controlling the bleeding, the \\
abdomen was closed. Uterine defects are a rare malformation that can cause a variety of obstetric problems in pregnant women, and \\
they must be closely monitored and treated in terms of cervical pregnancy growth. As the pregnancy week continues, life-threatening \\
bleeding may occur, and the patient may need a hysterectomy to stop the bleeding.
\end{tabular}

Keywords: cervical pregnancy, ectopic pregnancy, uterus didelphis, vaginal bleeding

\section{Introduction}

Genitourinary organ development begins in the $6^{\text {th }}$ week of embryological life (1). Although the prevalence of Mullerian duct anomalies has been reported at different rates, among these anomalies, the frequency of uterine didelphis (UD) is estimated to be $5 \%$. It is among the causes of infertility (2). The true incidence of congenital uterine anomalies is not known precisely, its prevalence in the general population is estimated to be between $0.001 \%$ and $10 \%$ (3). It is known that fertility and pregnancy outcomes of patients with Mullerian duct fusion anomaly are not good. The incidence of spontaneous abortion, premature birth, premature rupture of membranes and abnormal fetal presentation anomaly has increased in such patients (4).

Ectopic pregnancy is a disease seen in less than $2 \%$ of all pregnancies and is defined as implantation of the pregnancy product outside the uterine cavity. Although the most common type is tubal pregnancy (95\%), we also encounter a rare type, cervical pregnancy. The incidence of cervical pregnancy, which constitutes $0.1-0.2 \%$ of all ectopic pregnancies, is as rare as one in 10000 pregnancies (5-7). Cervical pregnancy occurs because of abnormal implantation of the blastocyst into the endocervical canal. It is among the crucial causes of maternal mortality and morbidity due to massive bleeding outcomes. Early diagnosis and treatment of cervical pregnancy are lifesaving, essential in terms of preserving fertility. Systemic methotrexate (MTX) or intra-amniotic potassium chloride $(\mathrm{KCl})$ is used in conservative treatment, but these conventional treatments can cause life-threatening bleeding during the procedure. In this presentation, we evaluated UD and cervical pregnancy's rare case with the literature findings' help.

\section{Case Report}

36-year-old pregnant admitted to our outpatient clinic with painless vaginal bleeding. In the anamnesis of the case, we have learned that she had been married for 16 years, her gravida was 5 , parity 4 , and living was 4 . She gave birth to her first three children by standard spontaneous vaginal delivery and her last child by cesarean section. A bilateral tubal ligation was performed in the previous cesarean section. She got remarried after, and laparoscopic tube reanastomosis was performed due to the request for a child. In the abdominal-obstetric ultrasonography (US) examination of the patient, uterus, double cervix, and double uterus, a $13+6$-week pregnancy with a positive fetal heartbeat was observed cervical canal in the right uterus (Fig. 1). The patient was informed about the possibility of UD during the US examination in her first pregnancy.

In the patient's speculum examination, there was active vaginal bleeding that caused a decrease in the hemoglobin value from 10.2 to $7.3 \mathrm{gr} / \mathrm{dl}$ within 2 hours, and the patient was performed d / c. Since the patient continued to bleed after dilatation curettage $(\mathrm{d} / \mathrm{c})$ and the bleeding did not respond to medical treatment, a hysterectomy was planned. Intraop uterus didelphys were observed, the right hemiuterus cervix was observed to be significantly enlarged (Fig. 2). Total right hemihysterectomy was performed after bilateral hypogastric artery ligation (Fig. 3). Inspired by this case, we questioned the association of 
UD and cervical pregnancy with the help of the literature (Fig. 3).

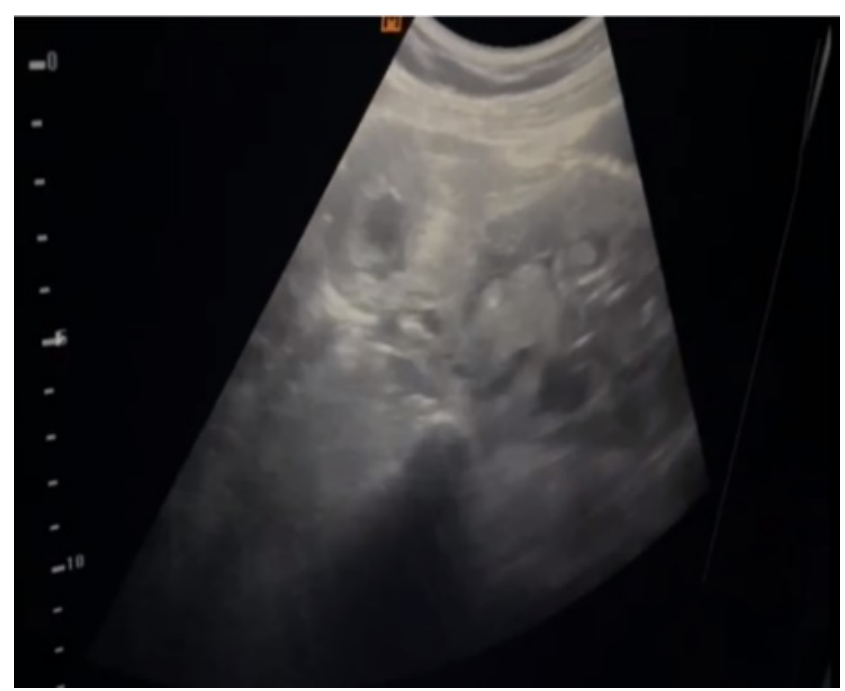

Fig. 1. USG evaluation of uterus to diagnose UD

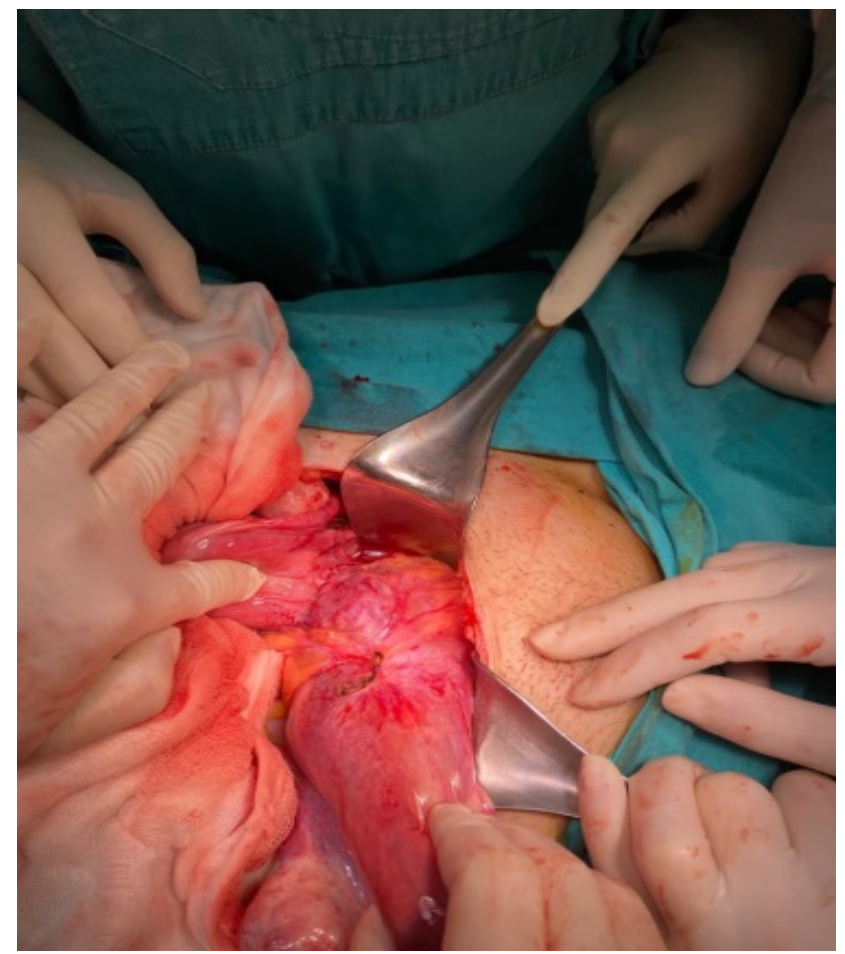

Fig. 2. The observation the right hemiuterus cervix

\section{Discussion}

The fusion of the two mullerian canals and the formation of the vaginal canal is completed between the $10^{\text {th }}$ and $17^{\text {th }}$ weeks $(9,10)$. Inadequate fusion of the Mullerian ducts causes the development of many uterine anomalies. Although the true prevalence of congenital uterine anomalies in the general population is not known exactly (11), the most common uterine anomaly is the uterine septus $(90 \%)$, followed by the bicornuate uterus $(5 \%)$ and UD (5\%) (3).

Detection of reproductive tract anomalies in early pregnancy is necessary for clinical follow-up (10). The most common symptoms of cervical pregnancy are vaginal bleeding (91\%) and groin pain (28\%), as in our case (6). In addition to clinical findings, $\beta$-hCG measurement, ultrasonography (USG), and magnetic resonance imaging (MRI) are used. Diagnosis is made by observing the gestational sac in the cervix, trophoblastic invasion of the cervical wall, and typical uterus dimensions on USG (6).

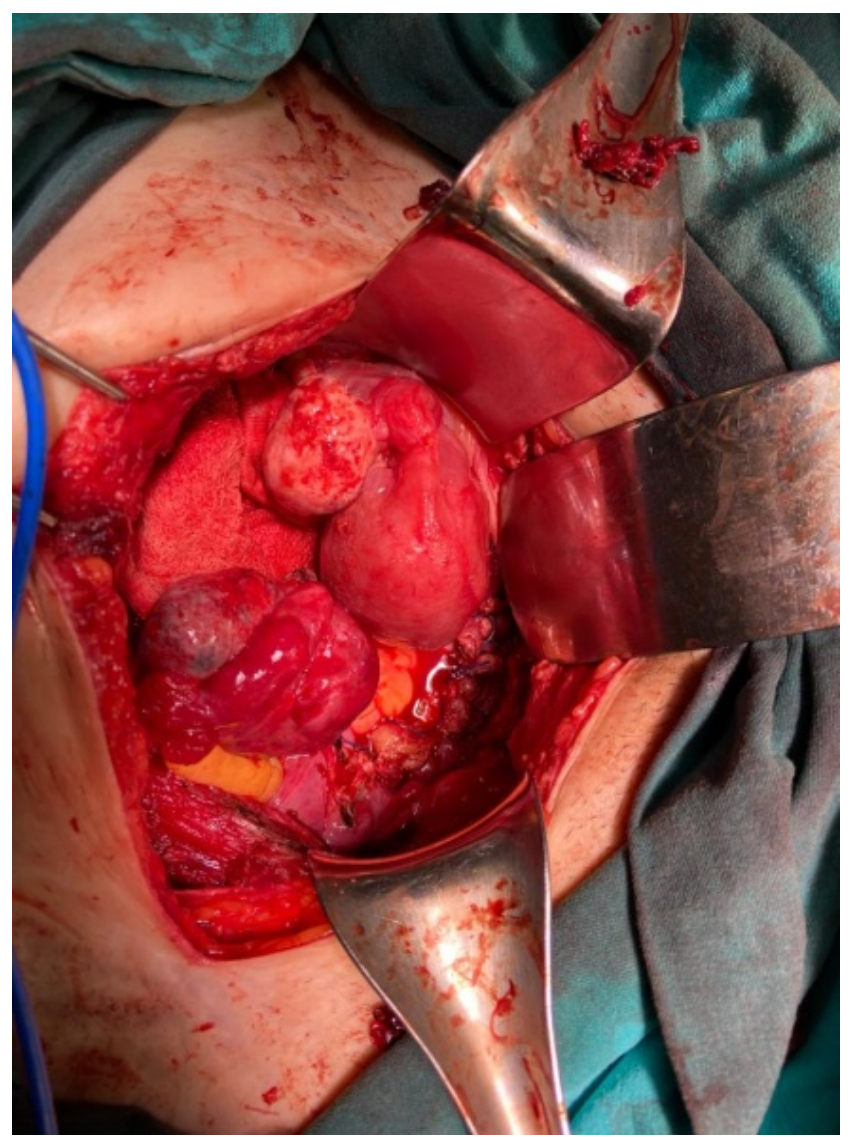

Fig. 3. The total right hemihysterectomy

In our case, uterine diadelphous and cervical ectopic pregnancy were observed together as a rare situation. Few cases have been reported on this subject in the literature (21-23). Patrick et al. managed a patient diagnosed with uterine diadelphous with a cervical pregnancy bHcg level of $6045 \mathrm{mIU} / \mathrm{ml}$ with vaginal bleeding at an early gestational week by administering methotrexate treatment. In our case, curettage was applied because methotrexate treatment was not appropriate due to the advanced gestational week (21). Another case study was reported by Chandrasekhar et al., two cases of UD, one cervical and the other cornual. Cervical located patient treated by applying intramuscular methotrexate after intraamniotic KCL application to 10 weeks of gestation. Cornual pregnancy resection was performed in the patient with 13 weeks of gestation in the cornual location (22). Like our case, a case of didelphus with advanced gestational week was reported by Haberal et al. In their case, supracervical hemihysterectomy was applied to the didelphus case with 18 weeks of placenta percrata (23).

Severe uterine bleeding may occur during conservative treatment in cervical ectopic pregnancies (13). Such a situation can be controlled by cervical curettage, 
intracervical foley catheter application after curettage and cervical suture. $(14,15)$. If vaginal bleeding occurs after medical treatment and fertility are desired to be preserved, effective bleeding control can be achieved by applying selective uterine artery embolization $(16,17)$. In cases where bleeding cannot be controlled, radical treatments such as internal iliac artery ligation, vaginal or abdominal hysterectomy can be applied (18-20). Since the diagnosis of cervical pregnancy is made more complex than other ectopic pregnancies, there may be delays in treatment. Delayed intervention often causes massive bleeding and may lead to emergency hysterectomy in approximately $50 \%$ of the cases, as in our case, too (12).

Uterine anomalies are rare malformation that can cause many obstetric complications in pregnant women. When the pregnancy week progresses, life-threatening bleeding may develop, and as in our case, the patient may occasionally undergo a hysterectomy for bleeding control.

\section{Conflict of interest}

None to declare.

\section{Acknowledgments}

None to declare.

\section{References}

1. Stassart JP, Nagel TC, Prem KA, Phipps WR. Uterus didelphys, obstructed hemivagina, and ipsilateral renal agenesis: the University of Minnesota experience. Fertil Steril. 1992; 57: 756-61.

2. Fatum M, Rojansky N, Shushan A. Septate uterus with cervikal duplication: rethinking the development of mullerian anomalies. Gynecol Obstet Invest. 2003; 55:18688.

3. Wai CY, Zekam N, Sanz LE Septate uterus with double cervix and longitudinal vaginal septum. A case report. J Reprod Med. 2001; 46:613-17,

4. Simon C, Martinez L, Pardo F, Tortajada M, Pellicer A. Mullerian defects in women with normal eproductive outcome. Fertil Steril. 199; 56192-93,

5. Breen JL. A 21 year survey of 654 ectopic pregnancies. Am J Obstet Gynecol 2002; 1 06:1004-19.

6. Ushakov FB, Elchalal U, Aceman PJ, Schenker JG. Cervical pregnancy: past and future. Obstet Gynecol Surv 1997; 52:45-59.

7. Vela G, Tulandi T. Cervical pregnancy: the importance of early diagnosis and treatment. J Minim Invasive Gynecol 2007; $14: 481-4$

8. Frates $\mathrm{MC}$, Benson $\mathrm{CB}$, Doubilet PM. Cervical ectopic pregnancy: results of conservative treatment. Radiology 1994; 19:773-5.

9. Narlavar RS, Chavhan GB, Bhatgadde VL, Shah JR. Twin gestation in one horn of a bicornuate uterus. J Clin Ultrasound. 2003;31:167-69,

10. Kanakas N, Boos R, Schmidt W. Twin pregnancy in the right horn of a uterus didelphys: a case report. Eur J Obstet Gyenecol Reprod Biol. 1989; 32:287-92.

11. Folch M, Pigem I, Konje JC. Mullerian agenesis: etiology, diagnosis and management. Obstet Gynecol Surv. 2000; 55:644-49.

12. Yitzhak M1, Orvieto R, Nitke S, Neuman-Levin M, BenRafael Z, Schoenfeld A. Cervical pregnancy a conservative stepwise approach. Hum Reprod 1999;14: 847-9.

13. Vela G, Tulandi T. Cervical pregnancy: the importance of early diagnosis and treatment. J Minim Invasive Gynecol 2007;14:481-4

14. Maral İ, Sözen U, Balık E. Servikal Gebeliğin Konservatif Tedavisi (Olgu Sunumu). Turk Klin Jinekol Obst.1993;3:67-9.

15. Papp Z, Tóth-Pál E, Papp C, Sziller I, Silhavy M, Gávai M, et al. Az arteria hypogastrica ligatura helye a kismedencei vérátáramlás csökkentésében, a vérzés csillapításában es a reproduktív képesség megorzésében 117 esetünk kapcsán [Bilateral hypogastric artery ligation for control of pelvic hemorrhage, reduction of blood flow and preservation of reproductive potential. Experience with 117 cases]. Orv Hetil. 2005 Jun 12;146(24):1279-85. Hungarian

16. Hirakawa $M$, Tajima $T$, Yoshimitsu $K$, Irie $H$, Ishigami $K$, Yahata $\mathrm{H}$, et al. Uterine artery embolization along with the administration of methotrexate for cervical ectopic pregnancy: technical and clinical outcomes. AJR Am J Roentgenol 2009; 192:1601-7.

17. Nakao $Y$, Yokoyama $M$, Iwasaka $T$. Uterine artery embolization followed by dilation and curettage for cervical pregnancy. Obstet Gynecol. 2008;111(2 Pt 2):505-7.

18. Samal SK, Rathod S. Cervical ectopic pregnancy. J Nat Sci Biol Med. 2015; 6: 257-60.

19. Alammari R, Thibodeau R, Harmanli O. Vaginal Hysterectomy for Treatment of Cervical Ectopic Pregnancy. Obstet Gynecol. 2017; 129:63-5.

20. Papp Z, Tóth-Pál E, Papp C, Sziller I, Silhavy M, Gávai M, et al. Bilateral hypogastric artery ligation for control of pelvic hemorrhage, reduction of blood flow and preservation of reproductive potential. Experience with 117 cases.Orv Hetil 2005; 146:1279-85.

21. Ng PC, Kann KS. Cervical Ectopic Pregnancy in a 23 Year Old with Uterus Didelphys. Clin Pract Cases Emerg Med. 2017 Jan 18;1(1):37-39.

22. Chandrasekhar C. Report of two cases of uterus didelphys and rare ectopic (cornual and cervical) pregnancies. Clin Imaging. 2007; ;31(1):57-61.

23. Tuştaş Haberal E, Çekmez Y, Ulu İ, Divlek R, Göçmen A. Placenta percreta with concomitant uterine didelphys at 18 weeks of pregnancy: a case report and review of the literature. J Matern Fetal Neonatal Med. 2016; 29(21):34458/ 